\title{
Minimising the Supervision Costs of the Organizations
}

\author{
Charles Ofiabulu, Oliver Charles-Owaba \\ Industrial and Production Engineering, University of Ibadan, Nigeria
}

\begin{abstract}
An Organisational structure is necessary as a framework for organising, planning, coordinating controlling and directing the organisational activities to achieve organisational goals Consequently, the organisational design problems have been formulated as that of minimisingcosts associated with supervision and coordination subject to some constraints with a heuristics as solution procedures. The difficulty of verifying the effectiveness of such heuristics in producing optimal organisation structures has created model acceptability problems. In this study, the concept of organisational work dynamics was used to reformulate supervision-cost function of a business organisation. Using this function, a dynamic programming version of the organisational design problem was defined and an associated algorithm developed. The performance (effectiveness and efficiency) of the algorithm was then compared to that of the existing heuristic. Also compared are the supervision-cost-based designed organisation structures and the existing organisational structure.
\end{abstract}

Keywords: - Dynamic programming, Cost Reduction, Organizational Design, Organizational structure, Supervision Costs.

\section{i. INTRODUCTION}

Most aspects of man-machine work systems have been designed using engineering principles with productivity improvement as the primary design criteria. Process design, operation design and facilities design appear to have received the good engineering attention, while, the design of organisation structure, the most important component of the work system that interrelates with others, has not received much engineering attention[1]. It is the human that develops the policies, plans and strategies for achieving organisational goals, decides on the skills, number of personnel per skill, materials, information, energy and machines combination to produce the goods and services with maximize productivity. The need for efficient utilisation of human work calls for a good labour organisation structure to achieve desired goals [2].

Consequently, different types of corporate governance structures and design tend to evolve across the globe $[1,2,3,4]$. The challenge of organisation design is to analyse and find the most suitable structure and design that will result into optimum performance and outcome of the constituting tasks such as control, planning, administration, monitoring, communication, maintenance and to a certain degree contracting [5].

Robbins and Coulter [3] defined organisational design as the process by which job/tasks are divided, grouped and coordinated for efficient and effective operations. Hinings and Greenwood [6]; Horling and Lesser [7]; Miller [8] and Robert [3] share similar views. The structure may be seen as a framework for decision making, the network for transmitting such decisions to the point where they are translated into action. An ideal structure should aid flow of information, materials, and tools, maximize personnel utilisation and minimize personnel redundancy for higher productivity

Some firms select their business organisational structure on the premise that structures evolve naturally (natural evolution), a "bench-marking" approach, that allows owners of business to adopt structures of other establishments on the conviction that what is working for establishment A is also good for B. In such cases, organization's structure design decisions are based on subjective opinion, intuition, and expert opinion. Other firms and researchers designed structures contingent on the data for the business situation (contingency approach). For years, it is the evolution theory that governed the process of specifying the structure of business organisations. In a more recent practice, the selection is restricted to a wide range of distinct forms of organisational structures identified by organisational scholars. Hax and Majluf, [2] explained that this school of thought lasted because "the present day organisational theory is 'soft' and largely lacks a quantitative structure that would lend itself to mathematical models."

It appears that the natural evolution approach to specifying a business organisation structure may not be adequate for a number of business situations. For example, knowledge-based economies, complexity and dynamism of business environments, and customers' behaviours have made simple selection of structures unsuitable. Some contingency factors were cited as being responsible [9]. Customers are no longer satisfied with standardized products; instead, they seek products and services that provide unique and desirable experiences. The application of scientific procedure, which considers the unique circumstances like the vision and goals of an organisation together with contingent data to specify an organisation structure, is formal design $[10,11]$. 
In designing organisation, concepts such as task, management coordination, and organization are framed into the design of the organisation structure $[12,13,1,2,7]$. The emphasis is on standardization of work, output, skills and supervision,. This is done by breaking down the tasks into elements at every workstation and measuring the available work in terms of time unit.

Charles-Owaba[13] formulated and solved the organisational design problem using the Operations Research paradigm with supervision cost as the objective function; the span of control, the number of management levels, number of managers/supervisors per level were the design variables while the number of the lowest cadre of personnel and human interaction dynamic factors were the design parameters. Large-scale applications of the model were not reported. One possible reason may be that the existing solution procedure, being a heuristic, cannot guarantee an optimal organisation structure. Associated with every heuristic is a problem of verifying model effectiveness and acceptance. People will accept a design model when they can easily verify that it is the best they are getting. The objective of this study is to reformulate the supervision cost model for organisational structure design, as a dynamic programming model and develop a solution procedure that guarantees optimal organisational structures with lowest supervision related costs.

\section{ii. NOTATION}

$\mathrm{A}_{\mathrm{ij}}$ : Number of hours per day by the worker at $\mathrm{j}^{\text {th }}$ position of the $\mathrm{i}^{\text {th }}$ level of the organisation in hours.

$b_{i j}$. Hourly rate of worker/decision maker at $j^{\text {th }}$ position of the $i^{\text {th }}$ level of the organisation in $\mathbf{A} /$ hour

$\mathrm{K}_{\mathrm{ij}}$ : The span of control is the number of subordinates at $(\mathrm{i}-1)^{\mathrm{th}}$ level that reports directly to boss at the

$\mathrm{j}^{\text {th }} \quad$ position of the $\mathrm{i}^{\text {th }}$ level of the organisation.

$\mathrm{L}_{\mathrm{ij}}$ : This is the average number of cases in for the attention of decision maker/boss at $\mathbf{j}^{\text {th }}$ position of the $\mathrm{i}^{\text {th }}$ level of the organisation.

$\overline{\mathrm{L}}_{\mathrm{ij}}$. $\quad$ This is the average number of cases that waited for the attention of decision maker/boss at $\mathbf{j}^{\mathbf{t h}}$ position of the $\mathrm{i}^{\text {th }}$ level of the organisation.

M : The highest level of the entire organisation for which $\mathrm{N}_{\mathrm{i}}=1$

$\mathrm{N}_{\mathrm{ij}}$. This is the number of positions of the $\mathrm{j}^{\text {th }}$ type at the $\mathrm{i}^{\text {th }}$ level of the organisational structure. This may be number of functional or divisional (j) managers or supervisors at the $\mathrm{i}^{\text {th }}$ level of the organisation $\mathrm{i}=0,1$, $2, \mathrm{M}$

$\mathrm{N}_{0 \mathrm{j}}$. Number of operation positions of $\mathrm{j}^{\text {th }}$ type at the $0^{\text {th }}$ level of the organisation

NL: $\quad$ Number of management levels of the entire organisational structure

NM: This is the number of positions at levels 2 and above of the organisational structure

NS: $\quad$ Number of first level managers or supervisors of the organisational structure

S: $\quad$ Organisational size is the total number of positions of the completely organisational structure.

SC: Average Span of control of managers is the number of subordinates per level.

$\mathbf{S}_{\mathbf{0}}$ : Operation position size of the organisation

$\mathrm{W}_{\mathrm{ij}}$ : This is the average waiting time of cases (from subordinate and the boss's superior) that came for the attention of the boss at the $\mathrm{j}^{\text {th }}$ position of the $\mathrm{i}^{\text {th }}$ level of the organisation.

$\lambda_{\mathrm{ij}}$. This is the rate at which the boss at the $\mathrm{j}^{\text {th }}$ position of the $\mathrm{i}^{\text {th }}$ level of the organisational structure is consulted by the subordinates.

$\mu_{\mathrm{ij}}$ : This is the rate at which the boss at $\mathrm{j}^{\text {th }}$ position and $\mathrm{i}^{\text {th }}$ level attend to cases that came for his attention. 
$\rho_{\mathrm{ij}}$. This is ratio of the cases' arrival rate to the service rate of cases for the boss at $\mathrm{j}^{\text {th }}$ position and $\mathrm{i}^{\text {th }}$

level. This is the measure of information traffic intensity between each boss at $\mathrm{j}^{\text {th }}$ position of the $\mathrm{i}^{\text {th }}$ level and his subordinates $a(i-1)^{\text {th }}$ levels and his superior at the $(i+1)^{\text {th }}$ level of the organisation.

$\mathrm{f}_{\mathrm{i}} \quad$ Annual supervision related cost function of $\mathrm{i}^{\text {th }}$ level of organisational structure.

F Annual supervision costs of operating the whole organizational structure.

\section{iii. ASSUMPTIONS}

1. Every employee is of normal health, highly motivated and at least, has one job to perform in the organisation;

2. The chance that personnel in a work unit will work most harmoniously is highest when the authority and responsibility to control the activities of the unit is assigned to one and only one boss at any given moment;

3. Standard workload (that is suitable for the position) and not maximum possible workload is assigned to every staff;

4. The organisation is a non-fully automated business organisation.

5. It is a personnel-personnel or personnel-machine interaction, stochastic and dynamic decision and operation work system;

6. The workload of a boss (superior) at decision center is proportional to his/her span of control ( $\left.\mathrm{K}_{\mathrm{ij}}\right)$;

7. Requests, response to directives, situational reporting, classifications, authorizations, counseling are features of superior-subordinate relationships;

8. Arrival of cases for and departure from the boss are stochastic events; which follows (FIFO) First come, first served consultation discipline;

9. The superior is experienced enough to handle a decision center. Otherwise, there will be a large heap of cases at every moment;

10. Data for parameter estimation are collected from the interaction stochastic and dynamic system, when it has passed from the transient to a steady state;

11. The time a case leaves its location and travels to the superior's desk is negligible.

\section{iv. SUPERVISION COST FUNCTION FORMULATION}

We considered a work dynamic system, which idealizes a business activity. A known number of workers report for work at the same time and work for a fixed number of hours daily. At the resumption hour, workers arrive, clock in and report to their respective duty posts. Assuming the one boss structure, each worker starts work if all necessary information and materials (assignments reports, authorizations, clarification, counselling, procedures, energy, funds, helper, and facilities) are available. When very essential information or material is not available at the duty post, he/she consults the unit's boss for it. He/she may be lucky to meet the boss at the time, obtain the required information, and return to work. Otherwise, he/she waits until the boss attends to his/her needs. Subordinates who earlier had consulted the boss may have other needs later. At the time of need, each worker consults the boss for it and may get the attention of the boss immediately or later, depending on whether the boss is free at the time.

In general, a superior may call emergently on his subordinate for meetings, report submission and discussion, some conflict resolution or other administrative reasons. These transactions leave the superior/subordinate in one of the many modes: telephone, memo/letter, e-mail, radio messages, close circuit television, computer, personal appearance, etc. We note here that there is human dynamics or action prompted by the requirements for some essentials or work information or materials.

Associated with these personnel activities are some form of costs, which we will call supervision costs. These are expenditures on personnel for salaries, fringe benefits, welfare packages and/or time spent waiting for materials, facilities information, etc. The goal of this section to develop a supervision costs model as function of human dynamics and organisational structure variables that is amenable to dynamic programming solution methods that will guarantee optimal structure.

Consider an organisation structure consisting of $\mathrm{j}=1,2,3, \ldots, \mathrm{J}$ positions and $\mathrm{i}=1,2,3, \ldots, \mathrm{M}$ decision levels. When $\mathrm{i}=0$, it is the level for the lowest cadre of workers; $i=1$, it is the supervisory level; $i>1$, it is pure decision position as depicted in Fig 3.1. 


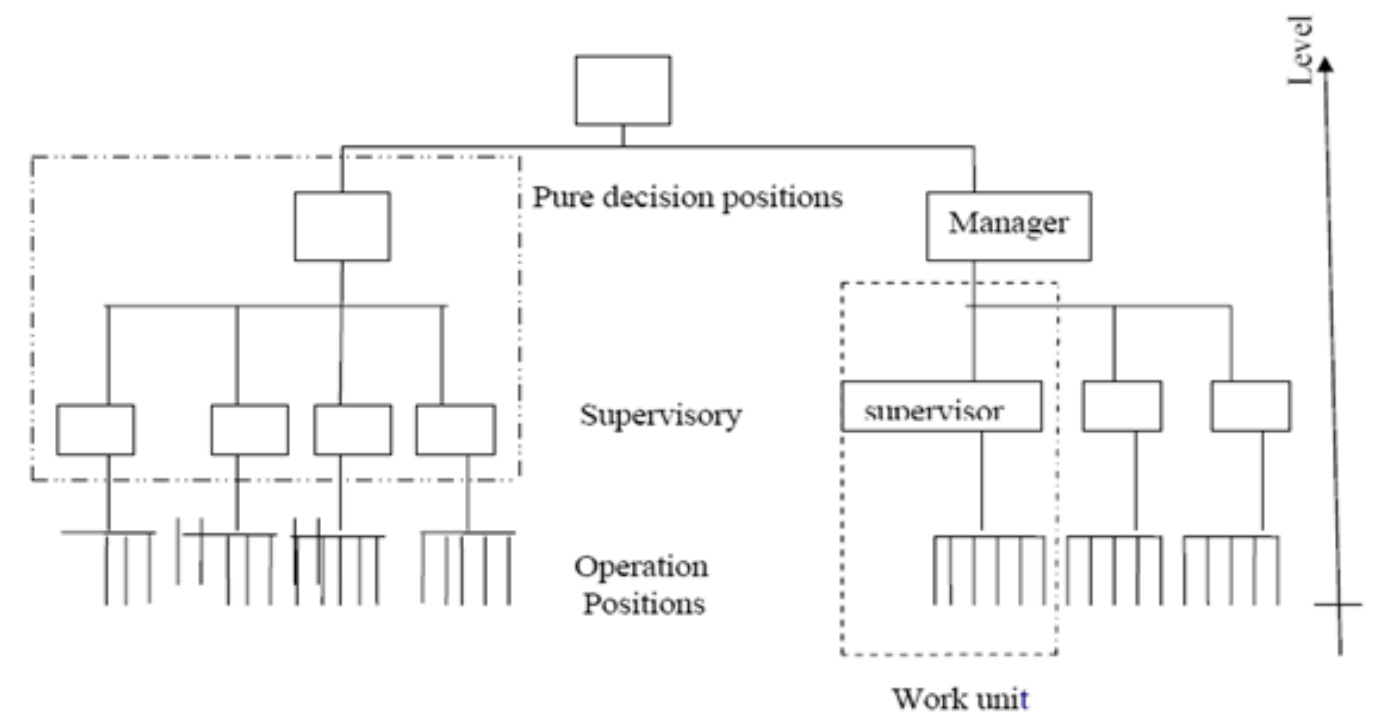

Figure 1 Organisational work units

For the work unit (Fig.1) at the $\mathrm{j}^{\text {th }}$ position of the $\mathrm{i}^{\text {th }}$ level with span of control (number of subordinates $K_{i j}$ ). The boss can be viewed as a server in a queuing system with finite source ( $K_{i j}$ subordinates under the boss). We consider the costs of wastes arising from the supervision and coordination activities in the organisational unit. These are costs of waiting time of the subordinates and idleness of the boss. The Supervision Cost is a hidden cost of lost times by the subordinates while waiting for the attention of the boss and the idle time of the boss who has very little job to do. For a work unit at $\mathrm{i}^{\text {th }}$ level and $\mathrm{j}^{\text {th }}$ position, the daily super vision cost DSC $_{\mathrm{ij}}$ is

$\operatorname{DSC}_{i j}=\left[b_{i-1, j} W_{i j} L_{i j}+b_{i j} P_{i j} A_{i j}\right]$

where:

$b_{i-1, j} W_{i j} L_{i j}$ is the daily cost of waiting for the attention of the boss.

$\mathrm{b}_{\mathrm{ij}} \mathrm{P}_{\mathrm{ij}} \mathrm{A}_{\mathrm{ij}}$ is the daily cost of idleness of the boss.

Using queuing theory we can define $\mathrm{P}_{\mathrm{ij}}, \mathrm{L}_{\mathrm{ij}}$ and $\mathrm{w}_{\mathrm{ij}}[14]$

The probability that no case require the attention of the boss (the boss is idle) is

$P_{i j}=\left[\sum_{n=0}^{1} C_{n}^{K_{i j}+2} n ! \rho_{i j}^{n}+\sum_{n=2}^{K_{i j}+2} C_{n}^{K_{i j}+2} n ! \rho_{i j}^{n}\right]^{-1}$

The average number of cases which came during the considered time $\mathrm{A}_{\mathrm{ij}}$ to receive the attention of the boss at position $\mathrm{j}$ of $\mathrm{i}^{\text {th }}$ level is given by

$L_{i j}=\sum_{n=0}^{K_{i j}+2} n P_{(n) i j}=\sum_{n=0}^{K_{i j}+2} C_{n}^{K_{i j}+2} n ! \rho_{i j} P_{i j}$

The average number of cases (type 1 and type2) which waited during the considered time $A_{i j}$ to receive the attention of the boss at position $\mathrm{j}$ of $\mathrm{i}^{\text {th }}$ level is

$\bar{L}_{i j}=\sum_{n=2}^{K_{i j}+2}(n-1) C_{n}^{K_{i j}+2} n ! \rho_{i j} P_{i j}$

The average waiting time of cases at position of the boss is

$W_{i j}=\frac{L_{i j}}{\hat{\lambda}_{i j}}=\frac{L_{i j}}{\lambda\left(K_{i j}-L_{i j}\right)}=\left(\frac{\breve{L}_{i j}+1-P_{i j}}{\mu_{i j}\left(1-P_{i j}\right)}\right)$

The traffic intensity $\rho_{\mathrm{ij}}=\frac{\lambda_{\mathrm{ij}}}{\mu_{\mathrm{ij}}}$

We define a fair structured organization as one in which the personnel at the same level carry the same responsibilities and reward. For a fair structured organization 
$\mathrm{K}_{\mathrm{i}, 1}=\mathrm{K}_{\mathrm{i}, 2}=\ldots=\mathrm{K}_{\mathrm{ij}}=\ldots=\mathrm{K}_{\mathrm{i}}$

$\lambda_{\mathrm{ij}}=\lambda_{\mathrm{i}}$, and $\mu_{\mathrm{ij}}=\mu_{\mathrm{i}}$.

$\mathrm{N}_{\mathrm{i}}=\sum_{\mathrm{J}=1}^{\mathrm{J}} \mathrm{N}_{\mathrm{ij}}=\frac{\mathrm{N}_{\mathrm{i}-1,}}{\mathrm{~K}_{\mathrm{i}}}$

The annual supervision cost at the ith level of a structured organisation is $\mathrm{f}={ }^{\wedge} \mathrm{y} \cdot \mathrm{DSC}_{\mathrm{i}}=\mathrm{yN}_{\mathrm{i}}\left[\mathrm{b}_{\mathrm{i}-1}, \mathrm{~W}_{\mathrm{i}} \mathrm{L}_{\mathrm{i}}+\mathrm{b}_{\mathrm{i}} \mathrm{P}_{\mathrm{i}} \mathrm{A}_{\mathrm{i}}\right]$

The total annual supervision cost of the $\mathrm{i}^{\text {th }}$ level of the organisation is given by equation 11 .

The total annual supervision cost of the organisational structure with values of $P_{i j},=P_{i} L_{i j}=L_{i}$ and $W_{i j}=W_{i}$ substituted is given be equation 12

$$
\begin{aligned}
& f=\left(y N_{i}\left[\frac{\left[\frac{\sum_{n=2}^{K_{i}}(n-1) C_{n}^{K_{i}} n ! \rho_{i}^{n}}{1+\sum_{n=1}^{K_{i}} C_{n}^{K_{i}} n ! \rho_{i}^{n}}+\left[1+\sum_{n=1}^{K_{i}} C_{n}^{K_{i}} n ! \rho_{i}^{n}\right]^{-1}\right.}{\left(1-\left[1+\sum_{n=1}^{K_{i}} C_{n}^{K_{i}} n ! \rho_{i}^{n}\right]\right.}\right] \frac{b_{i-1,}}{\mu_{i}}+\frac{b_{i} A_{i}}{1+\sum_{n=1}^{K_{i}} C_{n}^{K_{i}} n ! \rho_{i}^{n}}\right)
\end{aligned}
$$

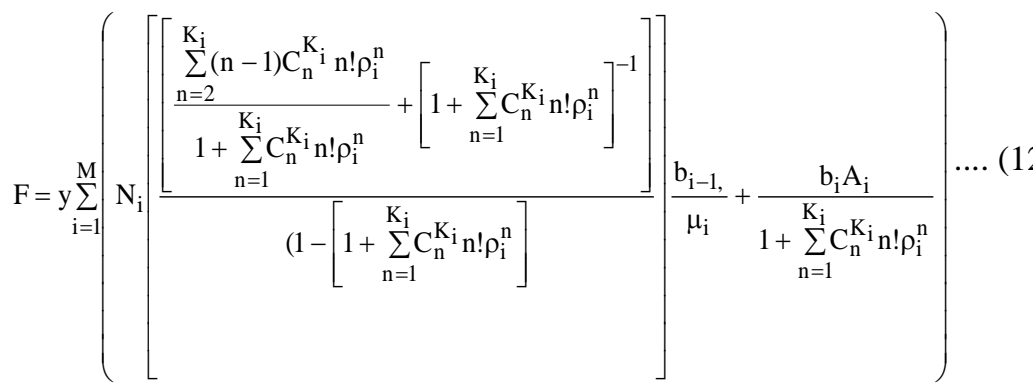

The daily supervision cost of organisation (F) and organisational level (f) are functions of the design parameters: consultation rate of the subordinates at level $\left(\lambda_{\mathrm{i}}\right)$, the rate at which the boss attends to the cases ( $\left.\mu_{i}\right)$, the hourly pay of the workers $\left(b_{i}\right)$, the number of operation positions $N_{0}$, the number of hours of work ( $\left.A_{i}\right)$. $F$ and $f$ are functions design variables: number of positions at the level $\left(N_{i}\right)$, the span of control $K_{i}$ per level and number of organisational levels $(\mathrm{M})$.

\subsection{Function Behaviour}

The total supervision cost function of an organisation $\boldsymbol{F}$ and total supervision cost function of organisational structure at any level $\mathrm{i}=1,2 \ldots \mathrm{M} f_{i}$ behaves as a convex function of span of control $\mathrm{K}_{\mathrm{ij}}$ at that level with following properties:

1. It is a function of variables $K_{i}$ and $N_{i}$ and parameters $\left.\mathrm{b}_{\mathrm{i}}, \lambda_{\mathrm{i}}, \mu_{\mathrm{i}}, \mathrm{A}_{\mathrm{i}}, \mathrm{N}_{0}\right)$ for all the levels $\mathrm{i}$ $(\mathrm{i}=1,2,3, \ldots, \mathrm{M})$ (see figure 2 ).

2. $K_{i}=23 . ., \forall i \mathrm{i}=1,2,3, . .,\left(K_{i}\right.$ is discrete $)$

3. F , $\mathrm{f}_{\mathrm{i}}$ are both strictly convex of a single variable function of $K_{i}$ once $N_{i-1}$ is known.

$\mathrm{F}, \mathrm{f}_{\mathrm{i}}$ are increasing linear function of $N_{1}$ (see figure 2) 


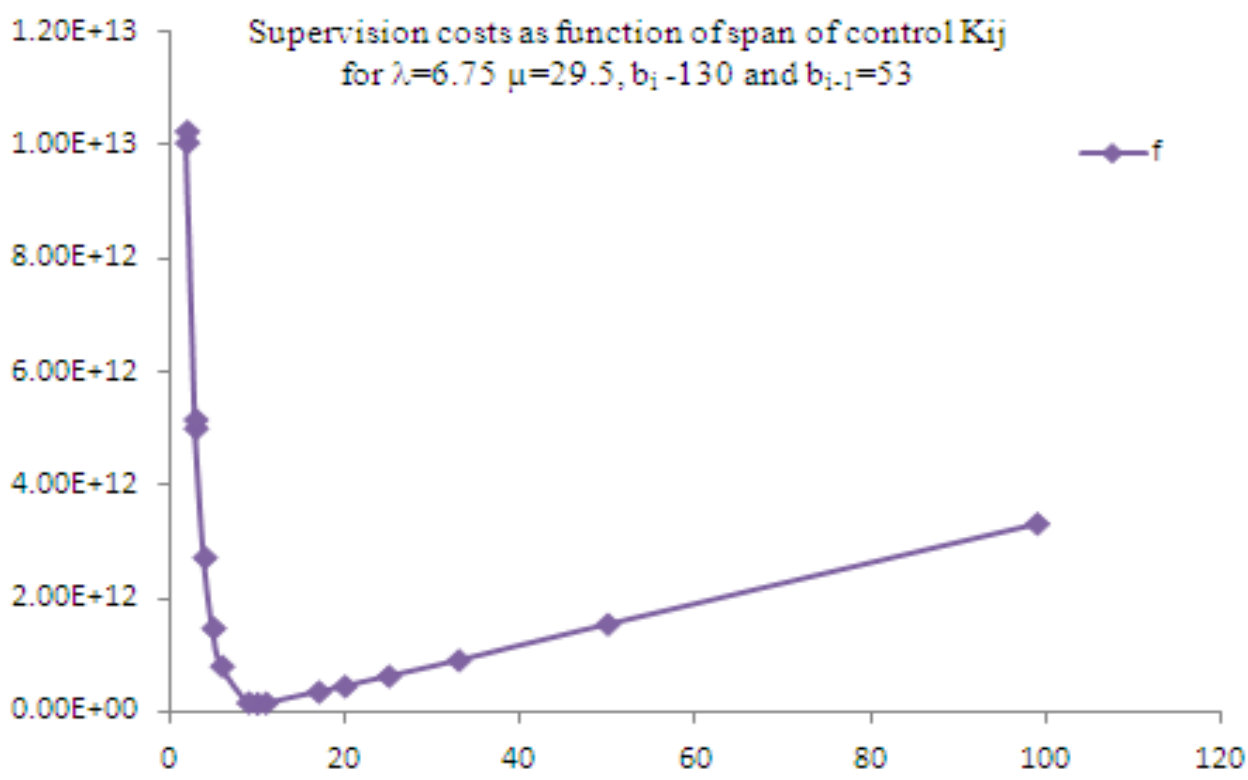

Figure 2 Supervision costs fi as function of span of control Ki

\subsection{Supervision Cost Based Organisational Design Problem}

Given the values of the parameter set $\theta$ determine the values for variables set $V=\left\{\mathrm{K}_{\mathrm{i}}, \mathrm{M}, \mathrm{N}_{\mathrm{i}}\right\}$ such that the Daily supervision cost of the organisation is the minimum value.

Minimise $F=D S C=f\left(M, K_{i}, N_{i}, \theta\right)$; where DSC is as given in equation 12

Subject to the following organisational design constraints:

$\mathrm{N}_{\mathrm{i}-1}=\mathrm{N}_{\mathrm{i}} \mathrm{K}_{\mathrm{i}} \ldots .$. Supervision Constraints

$\mathrm{N}_{\mathrm{M}}=1 \quad$ Apex positionsconstraint

$\mathrm{W}_{\mathrm{i}}\left(\mathrm{K}_{\mathrm{i}}, \mathrm{N}_{\mathrm{i}}, \phi\right) \leq \mathrm{A}_{\mathrm{ij}}$ Waiting timeconstraint

$\mathrm{N}_{\mathrm{i}}, \mathrm{K}_{\mathrm{i}}, \mathrm{M} \geq 0 \quad$ None negativityconstraints

\subsection{The Heuristic Solution}

The heuristics solution approach developed in Charles-Owaba (2002) is as outlined below:

Step 0: Determine the total number of operation positions $\mathrm{N}_{0}$, of a particular organisation and the available hours of work A

Step 1: Set the level of organisation $\mathrm{i}=1$

Step 2: Determine the $\mu_{\mathrm{i}}$ rate at which the boss attends to the subordinates and the rate at which the subordinates consults the boss, $\lambda_{i}$, for the level $i$

Step 3a: $\quad$ Substitute $N_{i}$ with $\frac{N_{i-1}}{K_{i}}$ in $D \mathrm{SC}_{i}$ equation 11

Step 3b: Compute the values of $\operatorname{DSC}_{i}$, functions for $K_{i j}$ values $2,3, \ldots \ldots N_{0}$ and determine the $K_{i j}$ for which the value of $\mathrm{DSC}_{i}$ functions is minimum for $\mathrm{DSC}_{i}$, and for which $W_{i j}$ is less than $A_{i j}$ and denote it as $K_{i j}^{*}$

Step 4: Determine the number of positions $\mathrm{N}_{\mathrm{i}}$ at level $i \mathrm{~N}_{\mathrm{I}}=\frac{\mathrm{N}_{\mathrm{i}-1}}{\mathrm{~K}_{\mathrm{ij}}^{*}}$

Step 5: If $N_{i}=1$ Go to Step 7

Step 6: Set $i=i+1$ and go to step 2

Step 7: $N_{M}=\frac{N_{M-1}}{K_{M j}^{*}} \mathrm{~N}_{\mathrm{M}}=1, N_{M-1}=\frac{N_{M-2}}{K_{M-1, j}^{*}}, \ldots \ldots \ldots \ldots \ldots \ldots . \ldots N_{1}=\frac{N_{0}}{K_{1 j}^{*}}$

Step 8: END 


\section{v. DYNAMIC PROGRAMMING DPAPPROACH}

The general dynamic Programming approach to problems is to optimize in stages.

We denote the level of the organisation as the stages with the span of control $\mathrm{K}_{\mathrm{i}}$ as the stage variables and the number of positions at the level $\mathrm{N}_{\mathrm{i}}$ as the stage decision variables.

The equation relating a stage to another is

$\mathrm{F}_{1}\left(\mathrm{i}, \mathrm{N}_{\mathrm{i}}, \mathrm{K}_{\mathrm{i}}, \theta_{1}\right)=\mathrm{f}_{\mathrm{i}}\left(\mathrm{i}, \mathrm{N}_{\mathrm{i}}, \mathrm{K}_{\mathrm{i}}, \theta_{1}\right)+\mathrm{F}_{\mathrm{i}-1}^{*}\left(\mathrm{i}-1, \mathrm{~N}_{\mathrm{i}-1}^{*}, \mathrm{~K}_{\mathrm{i}-1}^{*}, \theta_{1-1}\right)$

Where

- $\mathrm{F}_{\mathrm{i}}\left(\mathrm{i}, \mathrm{N}_{\mathrm{i}}, \mathrm{K}_{\mathrm{i}}, \theta_{1}\right)$ is the value of the criterion function (Daily Supervision Cost DSC) up to the level $\mathrm{i}^{\text {th }}$ of the organisation for any pairs of feasible of $\mathrm{N}_{i}$ and $\mathrm{K}_{\mathrm{i}}$ ( i.e. all $\mathrm{N}_{\mathrm{i}}$ and $\mathrm{K}_{\mathrm{i}}$ for which $\mathrm{N}_{\mathrm{i}} \mathrm{K}_{\mathrm{i}}=\mathrm{N}_{\mathrm{i}-1}$ and $\left.\mathrm{W}_{\mathrm{ij}}\left(\mathrm{N}_{\mathrm{i}}, \mathrm{K}_{\mathrm{i}}, \theta_{\mathrm{i}}\right) \leq \mathrm{A}_{\mathrm{i}}\right)$

- $\mathrm{f}_{\mathrm{i}}\left(\mathrm{i}, \mathrm{N}_{\mathrm{i}}, \mathrm{K}_{\mathrm{i}}, \theta_{\mathrm{l}}\right)$ is the value of the criterion function (Supervision Cost DSC ) at the $\mathrm{i}^{\text {th }}$ level of the organisation, for any pair of feasible of $N_{i}$ and $K_{i}$ (i.e. $N_{i} K_{i}=N_{i-1}$ and $W_{i j}\left(N_{i}, K_{i}, \theta_{i}\right) \leq A_{i}$ )

- $\mathrm{F}_{\mathrm{i}-1}^{*}\left(\mathrm{i}-1, \mathrm{~N}_{\mathrm{i}-1}^{*}, \mathrm{~K}_{\mathrm{i}-1}^{*}, \theta_{1-1}\right)$ is the minimum value of the function at the stage $\mathrm{i}-1$

- $\mathrm{N}_{\mathrm{i}-1}^{*}, \mathrm{~K}_{\mathrm{i}-1}^{*}$, are the optimal values at the $i-1$ stage of number of positions and span of control respectively

\subsection{Dynamic Programming Algorithm for Supervision CostMinimisation}

Step 1: Set $\mathrm{i}=0$ Determine the number of operation positions for each work type $\mathrm{N}_{0 \mathrm{j}}$ Compute the supervision cost at $\mathrm{o}^{\text {th }}$ level as $\mathrm{f}_{0}^{*}=0$ since there is no supervision that level. Allow a small integer variation of about $(\mathrm{DX}<3)$ on $\mathrm{N}_{0 \mathrm{j}}$ to ensure that enough factors of $\mathrm{N}_{0}$ are available for consideration especially when $\mathrm{N}_{0}$ is a prime number ( Note: that $\mathrm{N}_{\mathrm{i}} \times \mathrm{K}_{\mathrm{i}}=\mathrm{N}_{0}$ )

Step 2: Set $\mathrm{i}=1$ Determine the set of pairs of $\mathrm{N}_{1}$ and $\mathrm{K}_{1}$ for which $\mathrm{N}_{0}-\mathrm{DX} \leq \mathrm{N}_{1} \mathrm{~K}_{1} \leq \mathrm{N}_{0}+\mathrm{DX} \quad \forall \quad \mathrm{K}_{1}=2,3,4, \ldots \ldots \mathrm{N}_{0}$ and $\mathrm{W}_{1}\left(\mathrm{~N}_{1}, \mathrm{~K}_{1}, \theta\right) \leq \mathrm{A}$

Step: 3. For each pair of $\mathrm{N}_{1 \mathrm{j}}$ and $\mathrm{K}_{1 \mathrm{j}}$ determined in step 2. Compute the waiting time $\mathrm{W}_{1}\left(\mathrm{~N}_{1}, \mathrm{~K}_{1}, \theta_{1}\right)$ using equation 5. If $\mathrm{W}_{1}\left(\mathrm{~N}_{\mathrm{i}}, \mathrm{K}_{\mathrm{i}}, \theta_{\mathrm{i}}\right)>\mathrm{A}_{1}$ Discard the pair of $\mathrm{N}_{\mathrm{i}}$ and $\mathrm{K}_{\mathrm{i}}$ otherwise. Compute the supervision cost $\mathrm{f}_{\mathrm{i}}\left(\mathrm{N}_{\mathrm{i}}, \mathrm{K}_{\mathrm{i}}, \theta_{\mathrm{i}}\right)$ for all the feasible pairs of $\mathrm{N}_{\mathrm{i}}$ and $\mathrm{K}_{\mathrm{i}}$ using equation 12

Step: 4 For every $\mathrm{N}_{\mathrm{i}}$ and $\mathrm{K}_{\mathrm{i}}$ pair whose $\mathrm{f}_{\mathrm{i}}\left(\mathrm{N}_{\mathrm{i}}, \mathrm{K}_{\mathrm{i}}, \theta_{\mathrm{i}}\right)$ was determined in step 3 Calculate the $\mathrm{F}_{\mathrm{i}}\left(\mathrm{N}_{\mathrm{i}}, \mathrm{K}_{\mathrm{i}}, \theta_{1}\right)=\mathrm{f}_{\mathrm{i}}\left(\mathrm{N}_{\mathrm{i}}, \mathrm{K}_{\mathrm{i},}, \theta_{1}\right)+\mathrm{F}_{\mathrm{i}-1}^{*}\left(\mathrm{~N}_{\mathrm{i}-1}^{*}, \mathrm{~K}_{\mathrm{i}-1}^{*}, \theta_{1-1}\right)$ Write out for every $\mathrm{N}_{\mathrm{i}}$, and all the $\mathrm{F}_{1}\left(\mathrm{~N}_{\mathrm{i}}, \mathrm{K}_{\mathrm{i}}, \theta_{1}\right)$ and $\mathrm{K}_{\mathrm{i}} \mathrm{S}$ corresponding to each $F_{i}\left(N_{i}, K_{i}, \theta_{1}\right)$ Determine for every $N_{i}$ the minimum $F_{i}\left(N_{i}, K_{i}, \theta_{1}\right)$ in the case of supervision cost and denote it as $\mathrm{F}_{1}^{*}\left(\mathrm{~N}_{\mathrm{i}}, \mathrm{K}_{1}^{*}, \theta_{1}\right)$ Note also the value of $\mathrm{K}_{1}{ }^{*}$ corresponding to the $\mathrm{F}_{1}^{*}\left(\mathrm{~N}_{\mathrm{i}}, \mathrm{K}_{1}^{*}, \theta_{1}\right)$ Step;5 Determine the minimum $\mathrm{F}_{1}^{*}\left(\mathrm{~N}_{\mathrm{i}}, \mathrm{K}_{1}^{*}, \theta_{1}\right)$ for all the $\mathrm{N}_{\mathrm{i}}$ at the $\mathrm{i}$ stage and denote it as $\mathrm{F}_{1}^{* *}\left(\mathrm{~N}_{\mathrm{i}}, \mathrm{K}_{1}^{*}, \theta_{1}\right)$ If $\mathrm{F}_{1}^{* *}\left(\mathrm{~N}_{\mathrm{i}}, \mathrm{K}_{1}^{*}, \theta_{1}\right)$ corresponds to $\mathrm{N}_{\mathrm{i}}=1$, Go to step 10 If $\mathrm{F}_{1}^{* *}\left(\mathrm{~N}_{\mathrm{i}}, \mathrm{K}_{1}^{*}, \theta_{1}\right)$ corresponds to $\mathrm{N}_{\mathrm{i}} \geq 2$ Note $\mathrm{F}_{1}^{*}\left(\mathrm{~N}_{\mathrm{i}}, \mathrm{K}_{1}^{*}, \theta_{1}\right)$ for $\mathrm{N}_{\mathrm{i}}=1$ at this stage and denote as $\mathrm{L}^{*}\left(\mathrm{~N}_{\mathrm{i}}\right)$ and note its $\mathrm{K}_{1}^{*}$ value

Step:6 Set $\mathrm{i}=\mathrm{i}+1$ Determine the feasible pairs of $\mathrm{Ni}$ and $\mathrm{K}_{\mathrm{ij}}$ for which $\mathrm{N}_{\mathrm{i}} \mathrm{K}_{\mathrm{i}} \in\left\{\mathrm{N}_{\mathrm{i}-1}\right\}$

Step:7 For each pair of $\mathrm{N}_{1}$ and $\mathrm{K}_{1}$ determined as feasible in step 6 Compute the waiting time $\mathrm{W}_{\mathrm{i}}\left(\mathrm{N}_{\mathrm{i}}, \mathrm{K}_{\mathrm{i}}, \theta_{\mathrm{i}}\right)_{\mathrm{j}}$ using equation 5. If waiting time $\mathrm{W}_{\mathrm{i}}\left(\mathrm{N}_{\mathrm{i}}, \mathrm{K}_{\mathrm{i}}, \theta_{\mathrm{i}}\right)>\mathrm{A}_{\mathrm{i}}$, Discard the pair of $\mathrm{N}_{\mathrm{i}}$ and $\mathrm{K}_{\mathrm{i}}$ otherwise compute the supervision costs $f_{i}\left(N_{i}, K_{i}, \theta_{i}\right)$ for all the feasible pair of $N_{i}$ and $K_{i}$ using equation 3.40 $\mathrm{F}_{\mathrm{i}}\left(\mathrm{i}, \mathrm{N}_{\mathrm{i}}, \mathrm{K}_{\mathrm{i},}, \theta_{1}\right)=\mathrm{f}_{\mathrm{i}}\left(\mathrm{i}, \mathrm{N}_{\mathrm{i}}, \mathrm{K}_{\mathrm{i}}, \theta_{1}\right)+\mathrm{F}_{\mathrm{i}-1}^{*}\left(\mathrm{i}-1, \mathrm{~N}_{\mathrm{i}-1}^{*}, \mathrm{~K}_{\mathrm{i}-1}^{*}, \theta_{1-1}\right)$ for the feasible pair of $\mathrm{N}_{\mathrm{i}}$ and $\mathrm{K}_{\mathrm{i}}$ Write out for every $\mathrm{N}_{\mathrm{i}}$, and all the $\mathrm{F}_{1}\left(\mathrm{~N}_{\mathrm{i}}, \mathrm{K}_{\mathrm{i}}, \theta_{1}\right)$ and $\mathrm{K}_{\mathrm{i}} \mathrm{s}$ corresponding to each $\mathrm{F}_{1}\left(\mathrm{~N}_{\mathrm{i}}, \mathrm{K}_{\mathrm{i}}, \theta_{1}\right)$ Determine for every $\mathrm{N}_{\mathrm{i}}$ the minimum $\mathrm{F}_{1}\left(\mathrm{~N}_{\mathrm{i}}, \mathrm{K}_{\mathrm{i}}, \theta_{1}\right)$ in the and denote it as $\mathrm{F}_{1}^{*}\left(\mathrm{~N}_{\mathrm{i}}, \mathrm{K}_{1}^{*}, \theta_{1}\right)$ Note also the value of $\mathrm{K}_{1}^{*}$ corresponding to the 
$\mathrm{F}_{1}^{*}\left(\mathrm{~N}_{\mathrm{i}}, \mathrm{K}_{1}^{*}, \theta_{1}\right)$ Determine the minimum $\mathrm{F}_{1}^{*}\left(\mathrm{~N}_{\mathrm{i}}, \mathrm{K}_{1}^{*}, \theta_{1}\right)$ for all the $\mathrm{N}_{\mathrm{i}}$ at the $\mathrm{i}$ stage and denote it as $\mathrm{F}_{1}^{* *}\left(\mathrm{~N}_{\mathrm{i}}, \mathrm{K}_{1}^{*}, \theta_{1}\right)$

Step: 8 If $F_{1}^{* *}\left(N_{i}, K_{1}^{*}, \theta_{1}\right)$ corresponds to $N_{i j}=1$, Go to step 10 If $F_{1}^{* * *}\left(N_{i}, K_{1}^{*}, \theta_{1}\right)$ corresponds to $\mathbf{N}_{\mathbf{i}} \geq \mathbf{2}$.

Denote $\mathrm{Fl}_{1}^{*}\left(\mathrm{i}, \mathrm{N}_{\mathrm{i}}, \mathrm{K}_{1}^{*}, \theta_{1}\right)$ for $\mathrm{N}_{\mathrm{i}}=\mathbf{1}$ at this stage as $\mathrm{L}^{*}\left(\mathrm{~N}_{\mathrm{i}-1}=1\right)$ and note its $\mathrm{K}_{\mathrm{i}}$ value

Step: 9 Go To Step:6

Step: 10 If $F_{1}^{* *}\left(N_{i}, K_{1}^{*}, \theta_{1}\right)$ for $\left(N_{i}=1\right)$ is greater than $L^{*}\left(N_{i-1}\right)$ ( if it exists) Go To step 12

Step: $11 \mathrm{~F}_{1}^{* * *}\left(\mathrm{~N}_{\mathrm{i}}, \mathrm{K}_{1}^{*}, \theta_{1}\right)$ for $\mathbf{N}_{\mathrm{i}}=\mathbf{1}$ is the minimum supervision cost value of the organisational structure

- $\mathbf{i}$ is the number of level $\mathrm{M}$

- $\mathrm{N}_{\mathrm{M}}=1$

- $\mathrm{N}_{\mathrm{M}-1}=\mathrm{K}_{\mathrm{M}}^{*}$

- $\mathrm{N}_{\mathrm{i}-1}=\mathrm{N}_{\mathrm{i}} \mathrm{K}_{\mathrm{i}}^{*}$

-

- $\mathrm{N}_{0}=\mathrm{N}_{1} \mathrm{~K}_{1}^{*}$.

Step: $12 \quad \mathbf{F}^{* *}=\mathbf{L}^{*}\left(\mathrm{~N}_{\mathrm{i}-1}\right)$ is the minimum total supervision cost value of the organisational structure

- $\mathrm{i}-1=\mathrm{M}$ is the number of level $\mathrm{M}$

- $\mathrm{N}_{\mathrm{M}}=1$

- $\mathrm{N}_{\mathrm{M}-1}=\mathrm{K}_{\mathrm{M}}^{*}$

- $\mathrm{N}_{\mathrm{i}-1}=\mathrm{N}_{\mathrm{i}} \mathrm{K}_{\mathrm{i}}^{*}$

- $\quad$....................

- $\mathrm{N}_{0}=\mathrm{N}_{1} \mathrm{~K}_{1}^{*}$.

Step:13 End

\section{vi. APPLICATION}

The principles and the methodology outlined in sections 2 to 5 were applied in the redesign of an existing manufacturing firm. Data were collected using the work measurement principles to determine the values of human work and operation positions $\left(\mathrm{N}_{0}\right)$, consultation rate of the boss to his superior $\left(\lambda_{1}\right)$ and service rate $\left(\mu_{\mathrm{i}}\right)$ at each level. The existing organisational structure is presented in table 1 in terms of number levels, number of positions per level and span of control per level. The values of the related parameters and other information are presented in table 1 . The existing organizational structure has three departments with staff strength of 248: 46 decision positions; 204 operation positions and 4 organizational levels.

TABLE 1 Parameter values for Case 2

\begin{tabular}{|l|l|l|l|l|l|l|l|}
\hline & hours & \multicolumn{3}{|l|}{ Cases/ hour } & I hour & $\mathrm{Ni}$ & $\mathrm{Ki}$ \\
\hline Level & $\mathrm{A}$ & $\lambda_{1 \mathrm{i}}$ & $\lambda_{2 \mathrm{i}}$ & $\mu$ & $\mathrm{b}$ & $\mathrm{Ni}$ & $\mathrm{Ki}$ \\
\hline 4 & 8 & .0 .35 & 2.15 & 2.5 & 874.6 & 1 & 4 \\
\hline 3 & 8 & 0.31 & 1.25 & 1.75 & 583.33 & 4 & 3 \\
\hline 2 & 8 & 0.85 & 1.33 & 3.378 & 291.75 & & \\
\hline 1 & 8 & 0.13 & 0.94 & 4.37 & 197.4 & 29 & 7 \\
\hline 0 & 8 & - & - & - & 82.16 & 204 & - \\
\hline $\mathrm{N}_{0}=145$ & \multicolumn{7}{|l|}{} \\
\hline
\end{tabular}




\section{vii. RESULTS AND DISCUSSION}

The organisational structures and other characteristics of designs resulting from the solutions to design problem are presented in table 2 for dynamic programming and heuristic methods, as well as the existing structure. In addition, the DP algorithm and Heuristic computational times were curve fitted to and plotted against the Number of the operation positions in the organisations. The results are shown in expressions 14 and 15 and graphs presented in Fig.3.

$$
\begin{gathered}
\mathrm{T}_{\mathrm{DP}}=0.000259199-0.008002145 \mathrm{~N}_{0}+0.00035750721 \mathrm{~N}_{0}^{2} \\
-4.38122 \times 10^{-6} \mathrm{~N}_{0}^{3}+4.980177 \times 10^{-8} \mathrm{~N}_{0}^{4}
\end{gathered}
$$

and

$$
\begin{gathered}
\mathrm{T}_{\mathrm{H}}=-0.00363466+0.0250665 \mathrm{~N}_{0}-0.00020473 \mathrm{~N}_{0}^{2} \\
+7.6011868 \times 10^{-7}
\end{gathered}
$$

TABLE2Organizational characteristics for DP and $\mathrm{H}$ designed and the Existing organization

\begin{tabular}{|l|l|l|l|l|}
\hline S/No & Organizational characteristics & $\begin{array}{l}\text { Dynamic } \\
\text { Programming (DP) }\end{array}$ & Heuristic (H) & Existing \\
\hline 1 & Supervision cost & $2,093,510.00$ & $2,572,371.27$ & \\
\hline 2 & Number of levels & 3 & 3. & 4 \\
\hline 3 & Number of managers & 4 & 5 & 17 \\
\hline 4 & Number of supervisors & 18 & 21 & 29 \\
\hline 5 & Average span of control & 5.6 & 4.6 & 4 \\
\hline 6 & Organizational size & 167 & 171 & 248 \\
\hline 7 & Computation Time (seconds) & 14.89 & 1.65 & - \\
\hline
\end{tabular}

For the design criterion of minimising supervision cost, the Dynamic programming (DP) design algorithm produce smaller organizational structures as evident in the results presented in tables 2 The organizational size of the DP designed structure (167) was smaller than that of the heuristic designed (171) in the cases studied. The number of managers (4) and number of supervisors (18) for the DP are smaller than those of Heuristics designed (5) and (21) respectively. However, the average span of control of the DP-designed structure (5.6) is higher than the value (4.6) for the Heuristic-designed. The DP algorithm reduced the supervision cost from 2,572,371.27 units for Heuristic-designedto 2,093,510.00 units for DP-designed structures as indicated in table 2.

The reason for these differences is that DP algorithm, being an implicit enumeration, searches the entire solution space for the set of span of management, which will result in the global optimum for the design problem. The Heuristic, on the other hand, finds the optimal solution for each level and uses it as input to the next level. The optimal at stage 1 may induce sub optimality ant other stages. This is also evident in the solution values of all the objective function in which the values corresponding to the DP-designed structures are significantly better than those of the Heuristic designed (table2).

However, the computation time (14.89 seconds) for the implicit enumeration approach (the DP algorithm) is more than that of the Heuristic approach (1.65 seconds). It is clear from Fig.2, a plot of computation time and number of operation position that the DP algorithm time is polynomial function of the number of operation position $\mathrm{N}_{0}$ for range (40-140) while the heuristic computation tine is quadratic function the number of operation position $\mathrm{N}_{0}$ for the same range. These are shown in equations 13 and 15 . At this range of operating positions, the DP algorithm is relatively efficient since the literature defines efficiency in terms of the degree of polynomial or exponential curves[15,16].

However, whether or not it is efficient, the computation time is only in seconds ranging between 0.1 and 15.0. Hence, barring memory problems, for even large problems, organizational design with the DP algorithm may be feasible on Personal Computers. Relative to the existing structures of the cases examined, the DP designed algorithm reduced the, number of management levels, managers, and supervisors' form 4, 17, and 29 to 3,4 , and 18 respectively (see table 2 ). 


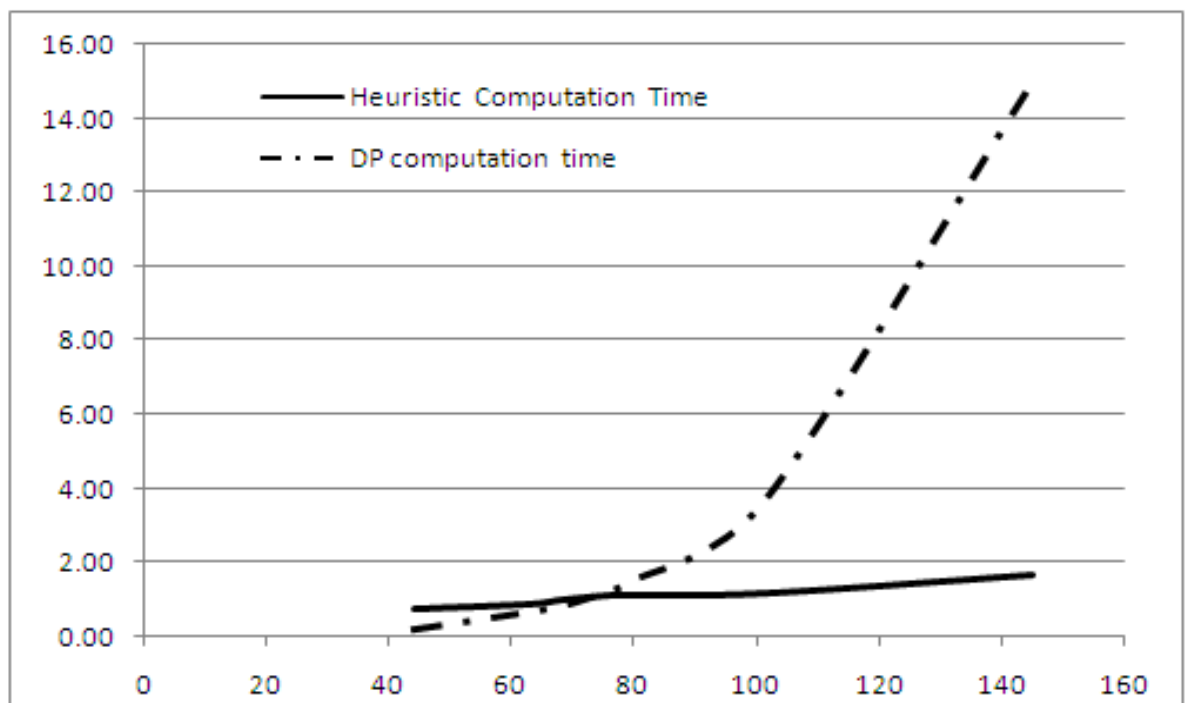

Figure 3 Computation times for Heuristic and DP algorithm

\section{viii. CONCLUSION}

Supervision cost function was defined in terms of the subordinate-superior consultation rate, superiorsubordinate service rate, unit cost of emolument and number of the lowest cadre of staff as design parameters while span of control, number of management levels and managers per level are the design variables.

The organisational structures resulting from 'dynamic programming algorithm' design method have lower supervision cost, workforce and management levels than those produced using the existing heuristic. The application of supervision cost minimization criterion for organisational design produced structures with significantly lower workforce and number of management levels than existing organisational structure. The heuristic computational time was lower than that of the dynamic programming algorithm. Both computation times are less than 15 seconds..

\section{REFERENCES}

[1] O. E. Charles-Owaba, Organisational Design: A Quantitative Approach. Ibadan: Oputuru books, 2002.

[2] Hax A. C. and Majiluf N. S., "Organisational Design: Survey and An Approach.," Operation Research, vol. 3, no. 29, pp. 417-447, 1981.

[3] J. Robert, Morden firm: Organizational design for performance and growth. New York: Oxford university press inc., 2004.

[4] Ofiabulu, C. E. and Charles-Owaba, O. E., "A personnel cost model for Organisational structure Designs," Industrial Engineering Letters, vol. 3, no. 6, p. 1=11, 2013.

[5] R. L Daft, Organization Theory and Design. Mason, OH, : South.Western, 2004.

[6] Hinings, C.R. and Greenwood, R., "The normative prescription of organizations," in Institutional Patterns and Organizations:Culture and Environment, L. G. Zucker, Ed. Cambridge, Mass: Ballinger Publishing Company.: Ballinger Publishing Company., 1988.

[7] Horling, B and Lesser, V., "Quantitative Organizational model for large-scale Agent system," in The international workshop on massively multi-agent system,., 2004, pp. 297-312.

[8] D. Miller, "Configuration of strategiy and structure: towards a synthesis," in Readings in Strategic Management, D. Asch, Ed. London: Macmillian, 1989.

[9] Larsen, E. R. and Lomi, A. , "Resetting the clock: a feedback approach to the dynamics of organisational inertia, survival and change," Resett The Journal of the Operational Reseach Society , vol. 50, no. 4 , pp. 406-421., 1999.

[10] Robert Kreitner, Foundation of Management: Basic and Best Practices.: Houghton Mifflin Company, 2005.

[11] Tushman, M. L. and Nadler, D. A., "Information processing as an integrating concept in organizational design," The Academy of Management Review, vol. 3., no. 3, pp. 613-624, 1978.

[12] O. E. Charles-Owaba, "On the Organizational structure Designs problem," Journal of Nigerian Institute of Industrial Engineers, vol. 1, no. 1, pp. 13-33, 1987.

[13] O. E. Charles-Owaba, "Optimal working-learning team size: a cost minimization model.," Journal of Nigerian Institution of Production Engineers., vol.., no.., p.., 1998.

[14] H. A. Taha, Operational Research: An introduction. New Jersey: Prentice Hall., 1986. 
[15] Johnson, D S, Gutin G, McGeoch L A, Yeo A, Zhang W and Zverovitch A, "Experimental Analysis of Heuristics for tha Asymetric Traveling Salesman Problem," in The Traveling Salseman Problem and its Variations, G. Gutin and H. Punnen., Ed. Ac: Kluwer Ac, 2002.

[16] Kwon, S Kin H and Kang M, "Determination of the candidate arc set for assymetric traveling salseman problem," Computer and Operations Research, vol. 32 , no. 5, pp. 1045-1057., 2005.

[17] H. Wildavsky, "Information As An Organizational Problem," Journal of Management Studies, vol. 20, no. 1, Jan. 1983.

[18] Robbins, S and Coulter, M., "Organizational Structure and Design," in Management, S and Coulter, M. Robbins, Ed. New York: PrenticeHall, 2002.

[19] Robbins,S and Coulter, M. , "Organizational Structure and Design. ," in Management. New York: PrenticeHall, 2002, p. chapter 10.

[20] Larsen, E. R. and Lomi, A., "Resetting the clock: a feedback approach to the dynamics of organisational inertia, survival and change," The Journal of the Operational Reseach Society, vol. 50 , no. 4, pp. 406-421., 1999. 